\title{
Chapter 9 \\ An International Collaborative Genetic Research Project Conducted in China
}

\author{
Yandong Zhao and Wenxia Zhang
}

\begin{abstract}
In 1995, a research team from a renowned US university started collecting blood samples from villagers living in Anhui province, China, with the cooperation of local research institutes and the Chinese government. In 2000, the US university team was accused of violating research ethics principles by not adequately informing the participants about the research and not sharing benefits fairly. Subsequent investigations by American and Chinese media and authorities showed that the US research institute, its research personnel and a pharmaceutical company involved were benefiting substantially from the project, while the Chinese research participants and the government were not. Three levels of exploitation can be distinguished in this case:

- the exploitation of local individual citizens as human research participants

- the exploitation of the local scientific community in China

- the exploitation of the country's national interest

In order to avoid such exploitation, high-income countries as well as low- and middle-income countries should strengthen their institutional arrangements and improve their cooperation mechanisms, in order to ensure that both sides benefit equally from international science and technology cooperation.
\end{abstract}

Keywords US genetic research team - China - Blood samples

Collaborative study $\cdot$ Exploitation

Y. Zhao $(\bowtie) \cdot$ W. Zhang

Chinese Academy of Science and Technbology for Development,

Yuyuantannalu No.8, 10038 Haidian District, Beijing, China

e-mail: zhaoyd@casted.org.cn

(C) The Author(s) 2018

D. Schroeder et al. (eds.), Ethics Dumping, SpringerBriefs in Research

and Innovation Governance, https://doi.org/10.1007/978-3-319-64731-9_9 


\section{Area of Risk of Exploitation}

Genetic studies in urban and rural areas in Anhui province are the topic of this case study. One of the reasons why the case shows a risk of exploitation is that Anhui is not as economically advanced as its neighbouring provinces. For example, in 2015, the GDP per capita in Anhui was CNY 35,997 (EUR 4,878) (Anhui 2016), far lower than that in the more developed neighbouring provinces, such as Jiangsu at CNY 87,995 (EUR 11,925) (Jiangsu 2016), Zhejiang at CNY 77644 (EUR 10,523) (Zhejiang 2016) and Hubei at CNY 50,520 (EUR 6,847) (Hubei 2016).

\section{Background}

Since the launch of reform and opening up in the 1970s, international science and technology (S\&T) cooperation has been an important means for lifting China's capability and level of S\&T innovation. It has also been an indispensable part of China's S\&T development. To promote international S\&T cooperation, the Chinese government has formulated a series of documents ${ }^{1}$ including the National Outline of International Scientific and Technological Cooperation in the Tenth Five-year Period; the Outline for the Implementation of International Scientific and Technological Cooperation Programme in the Eleventh Five-year Period; and the Special Programme on International Scientific and Technological Cooperation in the Twelfth Five-year Period. The national special programme on international S\&T cooperation was also added to the system of national S\&T programmes in 2001.

In pursuing international S\&T cooperation, China has upheld the principles of equality, mutual benefit and common development. From cooperation based on joint research projects in the earlier period to today's all-round cooperation covering skilled professionals, scientific bases and projects, China's international S\&T cooperation has grown and continues to grow in both breadth and depth. Through years of development, China has emerged as one of the most important partners for joint scientific research in the world, and has established cooperative relations on S\&T with more than a hundred countries and regions. Joint research efforts involving Chinese and international scientific research professionals are growing wider and deeper.

China's share of global science and engineering publications has pulled within a percentage point of those from the United States, according to the latest research statistics published by the US National Science Foundation (NSF) (Witze 2016).

\footnotetext{
${ }^{1}$ These documents (and others referred to later) are not available in English and have therefore not been included in the reference list.
} 
Of the 82 items in Top Ten News of Basic Research in China (later known as the Top Ten Scientific Advances in China) between 2005 and 2012, 43 (52\% of the total) are about international cooperation projects, while papers based on international cooperation account for 54\% of the 100 key academic papers in the relevant fields (Cheng et al. 2015).

Mr Jin Xiaoming, former director-general of the Department of International Cooperation of China's Ministry of Science and Technology, has pointed out that in a world where globalization is the trend in S\&T progress, an internationalization strategy is the only way to build China into an innovative country. Without internationalization or international cooperation, China will suffer immensely in its pursuit of advanced S\&T (Jin 2012).

For years, international S\&T cooperation has played an important role in facilitating China's S\&T progress, lifting the scientific research performance and international influence of Chinese scientists, and producing many successful examples of mutually beneficial cooperation. However, it is undeniable that problems of inequality and unfairness also exist in joint research projects, some of which have undermined the interests of the Chinese public and of the scientific community, and even China's national interests.

A strong case in point is that scientific research institutions and personnel from some high-income countries (HICs) have built on their advantages of capital and project experience to make the most of the eagerness of Chinese scientists to make their presence known in the international academic community, and have exploited the flaws and loopholes in China's existing laws and administration to engage in unethical R\&D activities in violation of international norms, scientific ethics and even Chinese laws. This has included:

- conducting clinical experiments on human research participants in China which are banned in HICs

- collecting samples in China for commercial purposes

- harvesting China's biological resources and undercutting the intellectual property rights of Chinese scientific research personnel

- conducting human experiments and/or collecting blood samples without providing sufficient information to the participants

- exploiting information asymmetries to conceal information about the experiments

- ignoring and violating the participants' rights to know

These problems are particularly serious in fields that undertake research on medical treatment, pharmacy, genetics, and environmental and air pollution, as well as research projects with potential commercial interests. The "genetic harvest" project conducted by the US University in collaboration with Chinese medical research institutions on farmers in Anhui province in the 1990s is a typical case in point. 


\section{Specific Case and Analysis}

On 20 December 2000, a Washington Post article titled "An isolated region's genetic mother lode" (Pomfret and Nelson 2000) disclosed that a Chinese American researcher of a renowned US University had been collecting blood samples from villagers living in the Dabie Mountains region of China's Anhui province since 1995 with the financial support of the National Institutes of Health (NIH) and biopharmacy companies. The blood samples were transferred to the US university's genetic bank for research into asthma, diabetes, hypertension and other diseases. Because of the value of these carefully selected blood samples to the research and development of new drugs, the US team received a large amount of research funding from international organizations. The report exposed the loss of China's genetic resources and triggered a stir both in China and worldwide.

The US university's genetic harvest project, conducted in Anqing city in Anhui province between 1994 and 1998, involved tens of thousands of farmers in eight counties. The project, led by an associate professor at the US university as the "chief scientist" conducted genetics studies on multiple diseases, including asthma, high blood pressure, obesity, diabetes and osteoporosis, while the experiments on asthma and hypertension were funded by the NIH (Pomfret and Nelson 2000; Xiong and Wang 2001, 2002).

The principal investigator from the US team also collaborated with a US pharmaceuticals company, and received its financial support. The project had three Chinese partners, Beijing Medical University, Anhui Medical University (AMU) and Anqing Municipal Bureau of Public Health. The US-based principal investigator started working with the AMU School of Public Health in 1993, and set up the Anhui Meizhong Bio-medicine and Environmental Health Institute in Anqing. The institute chose the Anqing Bureau of Public Health as its local partner, and selected the population groups suitable for taking samples based on grass-roots investigation. It collected blood samples through physical examination and acquired DNA samples of the target group for research purposes. The joint research project, which was conducted under the guise of free physical examinations for the farmers, mobilized the local population with the help of the local government. Blood samples were collected from farmers in the eight counties of Anqing city: Zongyang, Huaining, Qianshan, Tongcheng, Taihu, Wangjiang, Susong and Yuexi.

Media reports and the complaints of research personnel from the US university later exposed details of certain parts of the project that were suspected of compromising research ethics. The asthma project is an example: the approved number of participants was 2,000, but 16,686 were recruited. The research personnel also changed the amount of the financial subsidies for each recruit for food, travel and job leave allowances; this was intended to be USD 10 per day, but participants were paid an actual amount of only CNY 10 to CNY 20 per day (USD 1.50 to USD 3). In addition, the actual volume of each blood sample was much higher than approved. And the bronchodilators used were also different from what had been approved (Xiong and Wang 2002). 
According to the investigation by Chinese journalists, the collection of genetic samples had not been sanctioned by the relevant ethics committee in China (Xiong and Wang 2002). There were also serious breaches of the requirements to keep the participants informed. Many farmers who participated in the physical examination were not aware they were taking part in research. They were never shown or briefed about the "letter of informed consent", and did not sign or put their fingerprints on any such document. They did not even know which institution they had given their blood samples to, and nobody told them about the real purpose and results of their "physical examination" or the rights and benefits they were entitled to as part of their contribution to research. The asthma project was only one of the dozen human genetic research projects conducted by the US team in China. Other projects also involved the genetic screening of blood samples collected from Chinese farmers for the purpose of establishing the genetic links behind diseases like hypertension, diabetes, obesity and osteoporosis. Many of these projects were first supported by the US pharmaceutical company before NIH funds flowed in (Xiong et al. 2003).

In March 1999, the US University sent a team to China to ensure that the Anhui research was ethically and scientifically sound. Five months later, regulators from the US Department of Health and Human Services launched an investigation into the US university's genetic research in China. In March 2002, the department found that the genetic project in China seriously violated the regulations in multiple respects, including medical ethics, participant safety, and supervision and management (Yangcheng Evening News 2002). On 2 May 2003, the US university published the investigation results of the US government, which stated that there had been some procedural errors in supervision and record-keeping, but no participant was found to have been harmed in any way, so the school would not be penalized (HSPH 2003). Some biomedical experts and ethicists in China expressed regret about these results. They insisted that the studies had apparently violated basic research ethics, and called for a joint US-Chinese review of the experiments (Pomfret and Nelson 2000).

In this international research cooperation on a "genetic harvest", the actors and participants included both international and Chinese research institutes and research personnel, international companies, local government and the local residents who participated in the study.

During this cooperation, the US university, from its commanding position as a world-famous, authoritative international scientific research institute with first-class research personnel and advanced technologies, attracted the participation of Chinese partners and sold them the idea of building partnerships and the opportunity for co-authorship with US research personnel in return for the provision of genetic resources used for research purposes. As a result, they obtained access to a valuable pool of research data resources.

In 2003, the Chinese Ministry of Health and the Chinese Administration of Quality Supervision, Inspection and Quarantine jointly issued regulations limiting the export of special medical articles involving human genetic resources. However, most of the DNA samples the US team had collected in Anhui had already been shipped to the US. The principal investigator himself admitted that for the asthma 
research alone, 16,400 DNA samples had been transferred to the US (Zhao and Cai 2013). In 2002 and 2003, he set up a biopharmaceutical company and a biopharmaceutical research institute in China. Several Chinese research personnel who had participated in the genetic project in Anhui became his partners.

The US pharmaceutical company became the ultimate beneficiary after supplying research funds. As part of the agreement signed with the US university, they obtained the genetic information of Anhui farmers and claimed that it owned the relevant patents. In July 1995, the company announced that it was in possession of a large collection of asthma genetic samples from China. Soon afterwards, a large Swedish pharmaceutical company, invested USD 53 million in the pharmaceutical company for research into respiratory disease. The company's control of obesity and diabetes genes from China attracted another commitment of USD 70 million from a pharmaceutical giant. The stock price of the company soared from USD 4 per share, when it was listed in May 1995, to more than USD 100 per share in June 2000. Several of the company's senior executives earned a net profit of over USD 10 million each through trade in stocks (Xiong et al. 2003).

In striking contrast, the research participants from China received very few benefits from the project. Chinese research institutes and research personnel did gain the opportunity of working with renowned international research institutes, access to research funds and the co-authorship rights to scientific papers published in international academic journals - all of which appeal to most Chinese scientists but the local residents who participated in the studies received nothing but a free meal and an insignificant sum of money in travel and job leave allowances. In the words of a Chinese journalist, it was China's national interests and the unprotected Chinese farmers that were most harmed by the project, and it was the big US companies, research institutes and research personnel that received the real benefits (Xiong et al. 2003).

\section{Lessons Learned}

This case illustrates the dilemma faced by China and other low- and middle-income countries (LMICs) in conducting international S\&T cooperation. On the one hand, opening up and cooperation are an important means for LMICs to build their research capability and achieve faster development. On the other hand, given disadvantages in their capacity for S\&T innovation, including the ability to acquire information, and the inadequacy of ethical review and relevant governance systems, it is extremely difficult for them to develop equal partnerships with HICs in S\&T cooperation.

Although the academic communities of HICs have established a relatively mature system of ethical standards for scientific research, its research personnel, once working outside their home countries and in a relatively loose regulatory environment, can exploit the systemic loopholes and regulatory "vacuum" of a host country, intentionally or otherwise, and seek improper benefits through potentially 
illegal acts. In particular, in those research projects driven by commercial interests, when capital uses its economic and technological advantages to exploit resources and benefits from LMICs in the guise of scientific research, those countries find it difficult to resist. Different levels of exploitation might be found in this process, including the exploitation of local individual citizens as human research participants, of the local scientific community and of local countries' national interests.

What has happened in China is something many LMICs have probably experienced. Most of the cases of international institutions, companies and research personnel exploiting China's biological resources happened in the 1980s, the 1990s and the beginning of the 21 st century. This had a lot to do with China's inadequate management and regulatory system, the lack of substantive ethical review and insufficient awareness of the need to protect rights and interests during that period. In recent years, the Chinese government and the scientific community have gained a deeper understanding of this problem and have taken a series of positive measures.

In November 1998, the Chinese Ministry of Health established the Committee of Ethical Review on Bio-medical Research Involving the Human Body. To regulate international cooperation in genetics, China promulgated the Provisional Methods for the Management of Human Genetic Resources in 1998, which clearly stipulated that international cooperation on China's genetic resources must be conducted on the basis of equality and mutual benefit, with a formal agreement or contract, the approval of the Chinese government and informed consent in the collection of samples.

In 2003, the Chinese Ministry of Health and the Chinese Administration of Quality Supervision, Inspection and Quarantine jointly issued a notice which prescribed that special medical articles involving human genetic resources were not to be taken abroad without authorization. The Methods for the Ethical Review of Human-involved Bio-medical Research (Provisional) were promulgated in 2007.

We find that with the gradual improvement of relevant management rules and regulatory systems in China, the number of cases involving the exploitation of China's resources for biological research purposes is diminishing. China has strengthened the rules and regulations concerning intellectual property rights protection, generic resources protection and ethical review in international cooperation, enhanced the relevant management and supervision, and closed the loopholes in the administration of research.

At the same time, as China increasingly opens up to the world, its S\&T cooperation with international partners is also widening and deepening, and more and more overseas Chinese students are returning to China. All these factors have greatly mitigated the problem of knowledge and information asymmetry, and have enhanced public awareness of the need to protect rights and interests. As a result, there are fewer cases of HICs using their R\&D advantage to exploit China's resources through international cooperation.

In conducting international cooperation, LMICs can only reduce and prevent the occurrence of such cases when they are clear about their own resource advantages, build stronger awareness of the need to protect rights and interests, and improve the relevant management systems. In particular, in terms of the protection and 
utilization of traditional local knowledge and the protection of rights and interests related to biological resources generally, and genetic resources specifically, LMICs need clear awareness of these issues, while the international community should also give them more protection in this regard.

\section{Recommendations}

To reduce exploitation in international S\&T cooperation and conduct international cooperation truly on the basis of equality and mutual benefit, we must strengthen our efforts in the following respects:

- We need to foster a stronger awareness of mutually beneficial cooperation in the international community. Countries - big and small, rich and poor, developed and developing - must all uphold the established principles of equality, mutual benefit and sharing in international S\&T cooperation, and incorporate these principles into the framework of research ethics and responsible research and innovation.

- The research institutes and research personnel of HICs must abide strictly by the relevant international norms and ethical standards, especially international standards concerning the protection of human rights, and the participants' right to be informed, right to privacy and intellectual property rights. In this context, the regulatory agencies of HICs should strengthen not only the management and supervision of the irregularities happening in their own countries, but also the institutional design, in order to ensure effective supervision of improper acts committed by their research institutes and research personnel in research cooperation with other countries.

- LMICs should strengthen the building of ethical standards, promote knowledge of modern biotechnologies and enhance public awareness of the importance of protecting genetic resources, germplasm resources and patents in order to avoid falling into the trap of technological exploitation, manipulation and deprivation. In particular, they should be alert to the so-called joint R\&D activities of certain agencies and the personnel of HICs who might exploit the disadvantages of LMICs and regions - such as poverty, hunger and information asymmetry - in order to use these as the experimental subjects for research and the utilization of technologies without proper compensation. 


\section{References}

Anhui (2016) Statistical bulletin on national economic and social development in Anhui province in 2015. Anhui Provincial Bureau of Statistics, 25 February [in Chinese]. http://www.ahtjj.gov. cn/tijj/web/info_view.jsp?strId=1461911669310505\&_indextow=8

Cheng Y, Liu Y, Wang W (2015) Empirical research on international S\&T cooperation promoting the Annual Conference of China Soft Science. Beijing

HSPH (2003) HSPH issues the US government's findings on the school's genetic research in China. Medicine and Philosophy 24(9):46

Hubei (2016) Statistical bulletin on national economic and social development in Hubei province in 2015. Hubei Provincial Bureau of Statistics, 26 February. http://www.stats-hb.gov.cn/tjgb/ ndtjgb/hbs/112361.htm

Jiangsu (2016) Statistical bulletin on national economic and social development in Jiangsu province in 2015. Jiangsu Provincial Bureau of Statistics, 29 February. http://www.js.gov.cn/ jszfxxgk/tjxx/201602/t20160229492951.html

Jin X (2012) China's internationalization strategy for science and technology and current status of international scientific and technological cooperation [in Chinese]. Science \& Technology Industry Parks 11:25-27

Pomfret J, Nelson D (2000) An isolated region's genetic mother lode. Washington Post, 20 December. $\quad$ http://www.washingtonpost.com/wp-dyn/content/article/2008/10/01/ AR2008100101158.html

Witze A (2016) Research gets increasingly international. Nature, 19 January. http://www.nature. com/news/research-gets-increasingly-international-1.19198

Xiong L, Wang Y (2001) A suspicious international project of genetic studies. Outlook Weekly 13:24-28

Xiong L, Wang Y (2002) Harvard University's genetic research in China is illegal. Outlook Weekly 15:48-50

Xiong L, Wang Y, Wang C (2003) Poaching China's genetic resources: re-investigating the Harvard genetic project. Outlook Weekly 38:22-25

Yangcheng Evening News (2002) US government: there are serious moral problems in human studies of Harvard. 5 April. http://news.sohu.com/13/95/news148409513.shtml

Zhao X, Cai Z (2013) Social process and development mechanism on biopiracy; case studies from the perspective of constructivism. Studies in Science of Science 31(12)

Zhejiang (2016) Statistical bulletin on national economic and social development in Zhejiang province in 2015. Zhejian Provincial Bureau of Statistics, 24 March. http://www.zj.gov.cn/art/ 2016/3/24/art_5497_2075286.html

\section{Author Biographies}

Yandong Zhao is director of the Institute of Science, Technology and Society of the Chinese Academy of Science and Technology for Development, CASTED, a research arm of the Ministry of Science and Technology.

Wenxia Zhang is a senior researcher at the Institute of Science, Technology and Society of the Chinese Academy of Science and Technology for Development CASTED, a research arm of the Ministry of Science and Technology. 
Open Access This chapter is licensed under the terms of the Creative Commons Attribution 4.0 International License (http://creativecommons.org/licenses/by/4.0/), which permits use, sharing, adaptation, distribution and reproduction in any medium or format, as long as you give appropriate credit to the original author(s) and the source, provide a link to the Creative Commons license and indicate if changes were made.

The images or other third party material in this chapter are included in the chapter's Creative Commons license, unless indicated otherwise in a credit line to the material. If material is not included in the chapter's Creative Commons license and your intended use is not permitted by statutory regulation or exceeds the permitted use, you will need to obtain permission directly from the copyright holder.

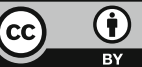

